Thorax (1975), 30, 582.

\title{
An intrapulmonary teratoma associated with thymic tissue
}

\author{
D. W. D A Y and S. A. T A Y L O R \\ Departments of Morbid Anatomy and Surgery, King's College Hospital, \\ Denmark Hill, London SE5 $8 R X$
}

\begin{abstract}
Day, D. W. and Taylor, S. A. (1975). Thorax, 30, 582-587. An intrapulmonary teratoma associated with thymic tissue. A benign teratoma was removed by segmental resection from the upper lobe of the right lung in a girl aged 19 years. This is the twentieth case report of a teratoma occurring in the lung substance and is of especial interest because of the identification of thymic tissue histologically. The significance of this in relation to the pathogenesis of intrathoracic teratoma is discussed.
\end{abstract}

Only 19 cases of intrapulmonary teratoma have been reported in the world literature. Thymic tissue has not been described in them. We wish to report a case in which thymic tissue was present.

\section{CASE REPORT}

A 19-year-old female clerk was admitted on 21 July 1974 after referral from another hospital. She had noticed intermittent pain in the right chest for two years and for three months a cough with purulent sputum and right-sided pleuritic pain. There had been no haemoptysis and she had not lost weight. A chest radiograph two months before admission showed a round shadow adjacent to the right hilum and this subsequently increased in size. Other investigations included a haemoglobin of $13.6 \mathrm{~g} / \mathrm{dl}$, a normal total and differential white blood cell count and an ESR of $30 \mathrm{~mm}$ in one hour (Westergren). A tuberculin test was positive and because the radiological appearances suggested a tuberculous adenitis, antituberculous treatment with rifampicin and isoniazid was started, but the hilar shadow continued to enlarge (Fig. 1).

On examination after referral she was a fitlooking girl without signs in the chest. A culture of the sputum grew commensal organisms only. Tomography localized the lesion to the right upper lobe. A bronchoscopy showed no abnormality and the preoperative diagnosis was of a tuberculoma.

On 25 July 1974 a right posterolateral thoracotomy was performed and a mass measuring approximately $5 \times 4 \times 2 \mathrm{~cm}$ was found in the anterior segment of the right upper lobe, partiallg adherent to the mediastinum. During mobilization it discharged yellow sebaceous material. A stan dard anterior segmental resection was done an\$ the chest was closed with drainage. The patien made an uneventful postoperative recovery.

The resected segment of lung measure $\Phi$ $11 \times 5 \times 5 \mathrm{~cm}$, and at one pole under the pleurat surface was an encapsulated partially cystie mass measuring $6 \times 4 \times 3 \mathrm{~cm}$, from the lining of which a white polypoid structure arose. This ex을 tended into the distal part of the segmental bronchus which was bronchiectatic (Fig. 2). The cut surface showed tissue around the cystic spacê. up to $1.5 \mathrm{~cm}$ thick with a variable yellow an white appearance, and sebaceous material was present around the stalk of the polyp. Thus the cystic space of the teratoma was in direct con tinuity with the distal part of the segmenta bronchus. The lung tissue surrounding thes bronchiectatic area of the bronchus was yellow and firm.

Histologically the proximal part of the sego mental bronchus was lined by normal respirator epithelium which in the bronchiectatic segmeno showed some squamous metaplasia with areas of ulceration. The surrounding lung tissue showed lipoid pneumonia, and the interstitial tissues and alveoli were packed with foamy multinucleate $\$$ giant cells. When traced distally into the cystio cavity of the teratoma the epithelium was prę dominantly of keratinizing stratified squamous type beneath which were hyperplastic sebaceous 


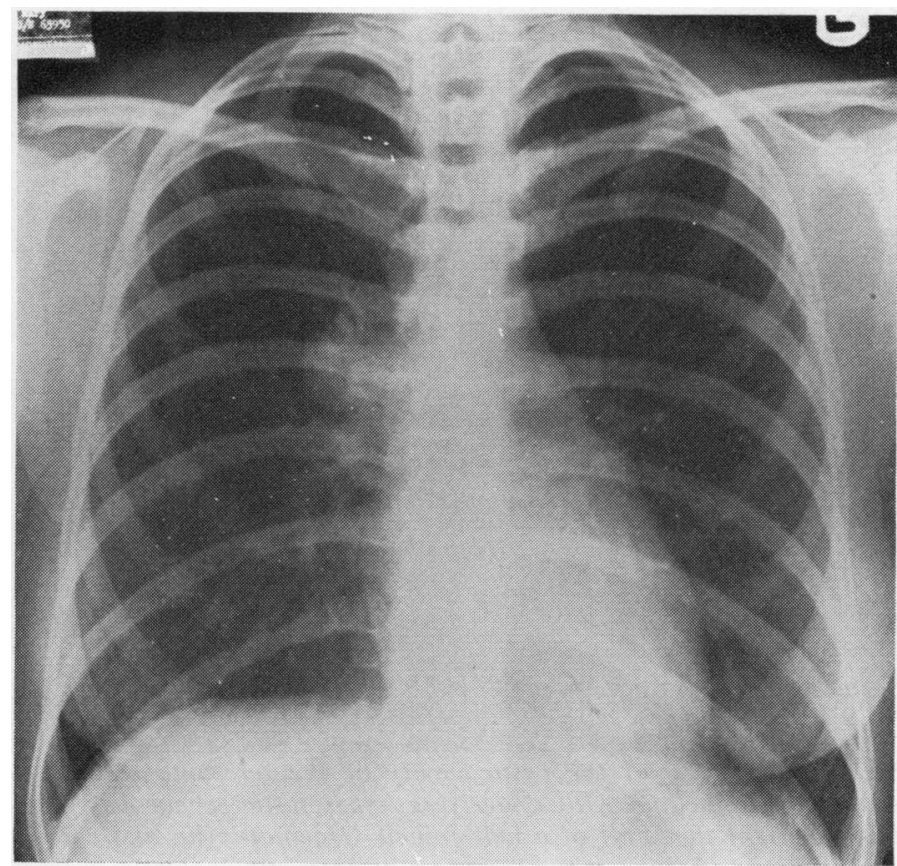

FIG. 1. A postero-anterior chest radiograph showing a rounded opacity in the right hilar region.

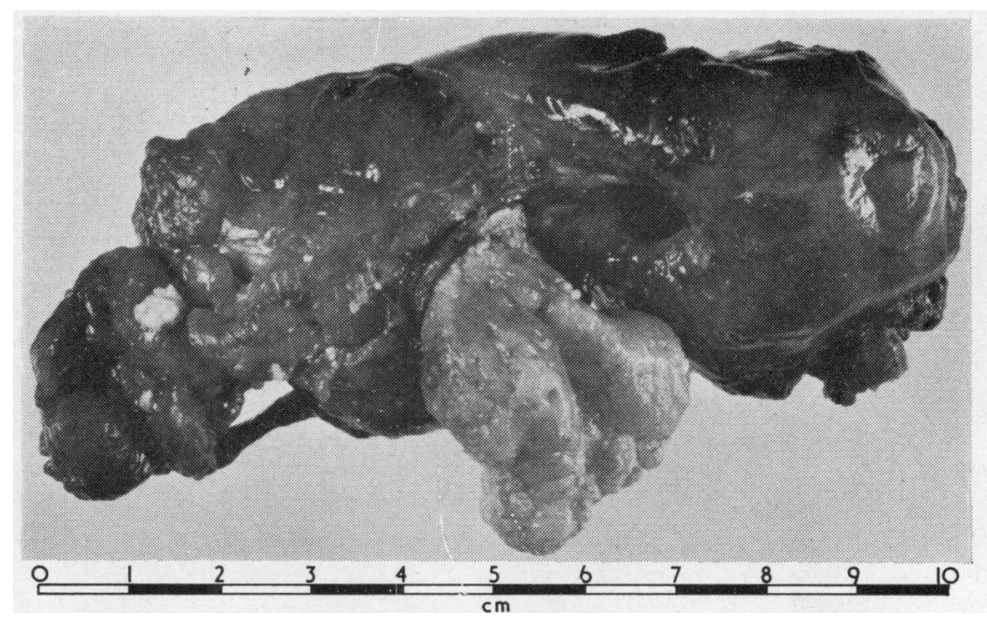

FIG. 2. The operative specimen showing the teratoma on the left. In the centre is the polypoid structure which has been displaced from the bronchiectatic cavity seen above and to its right. 


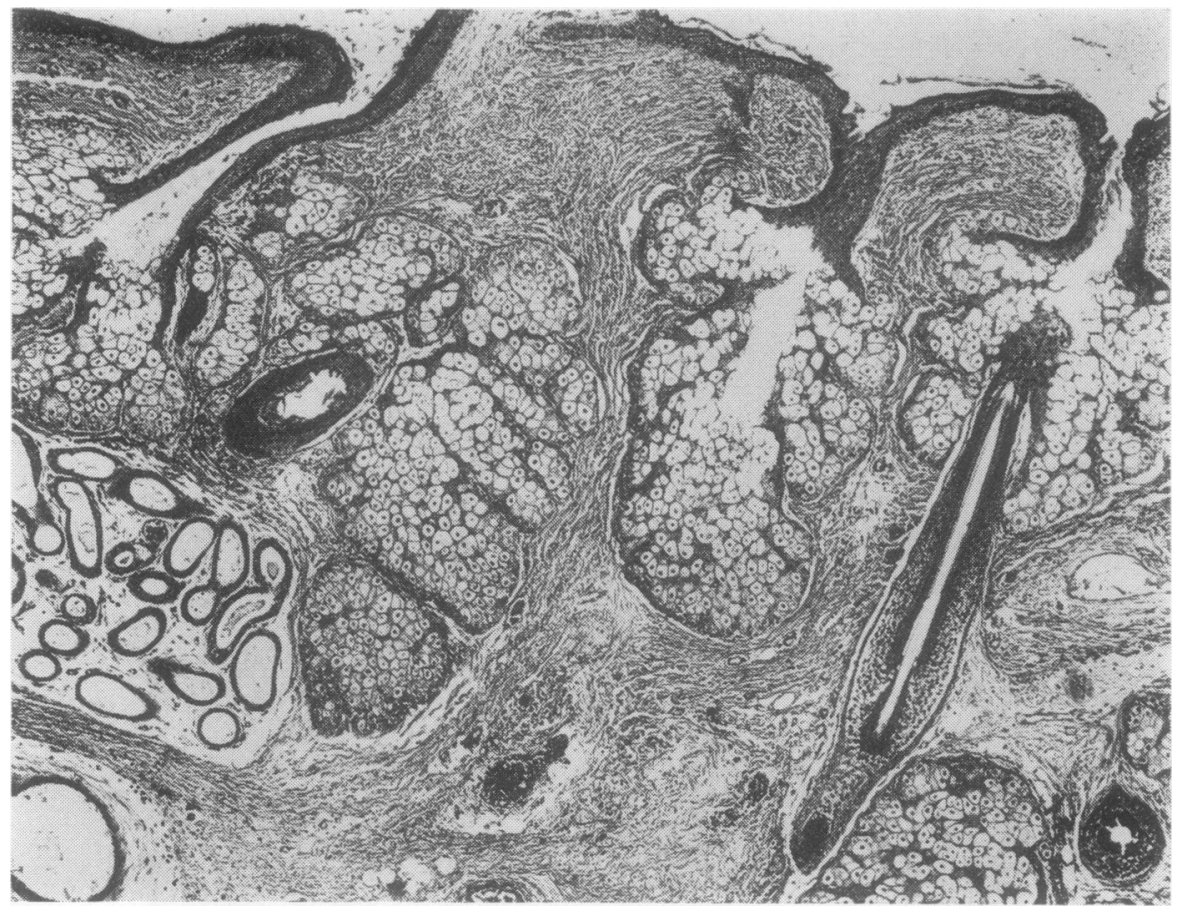

FIG. 3. Part of the lining of the cystic cavity of the teratoma showing keratinizing stratified squamous epithelium with underlying hyperplastic sebaceous glands and sweat ducts, and to the right the shaft of a hair follicle (Haematoxylin and eosin $\times 50$ ).

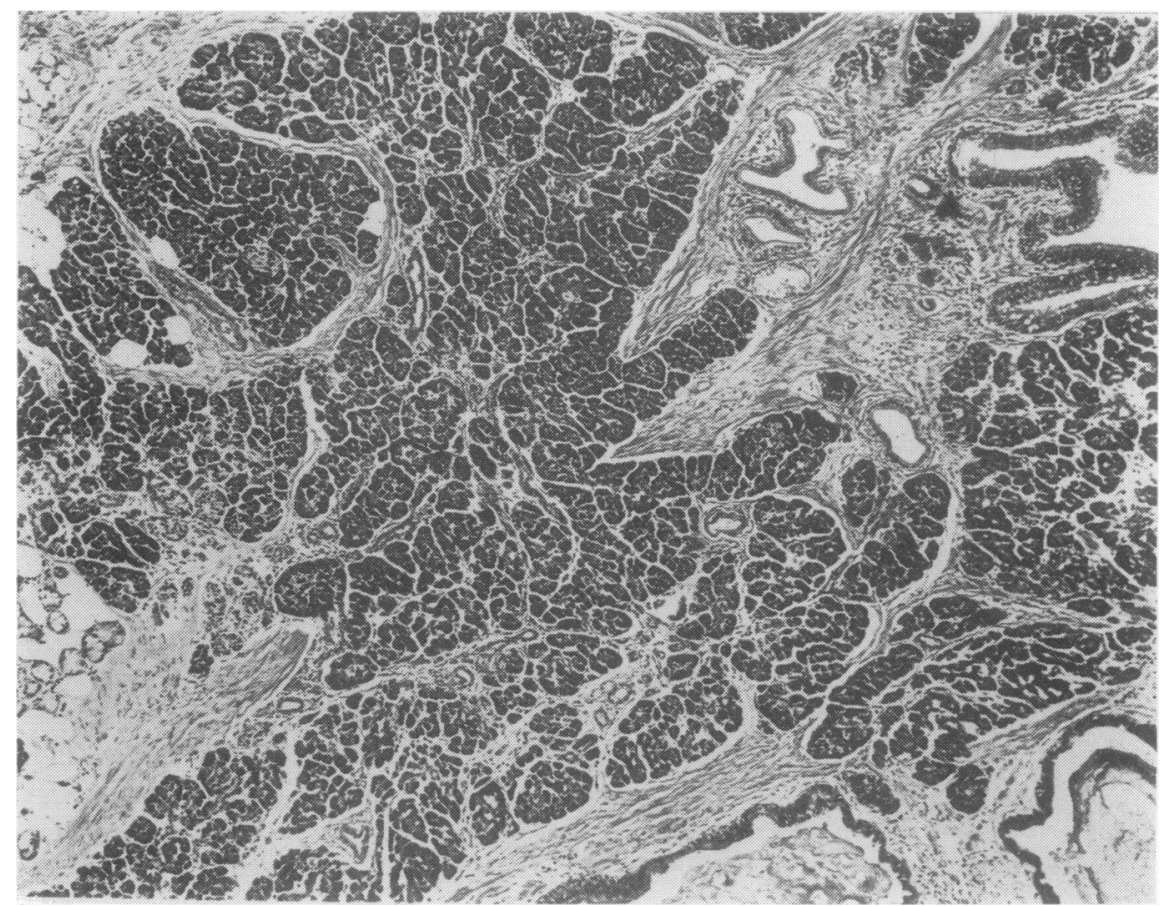

FIG. 4. Pancreatic acinar tissue and adjacent epithelial structures (Haematoxylin and eosin $\times 50$ ). 


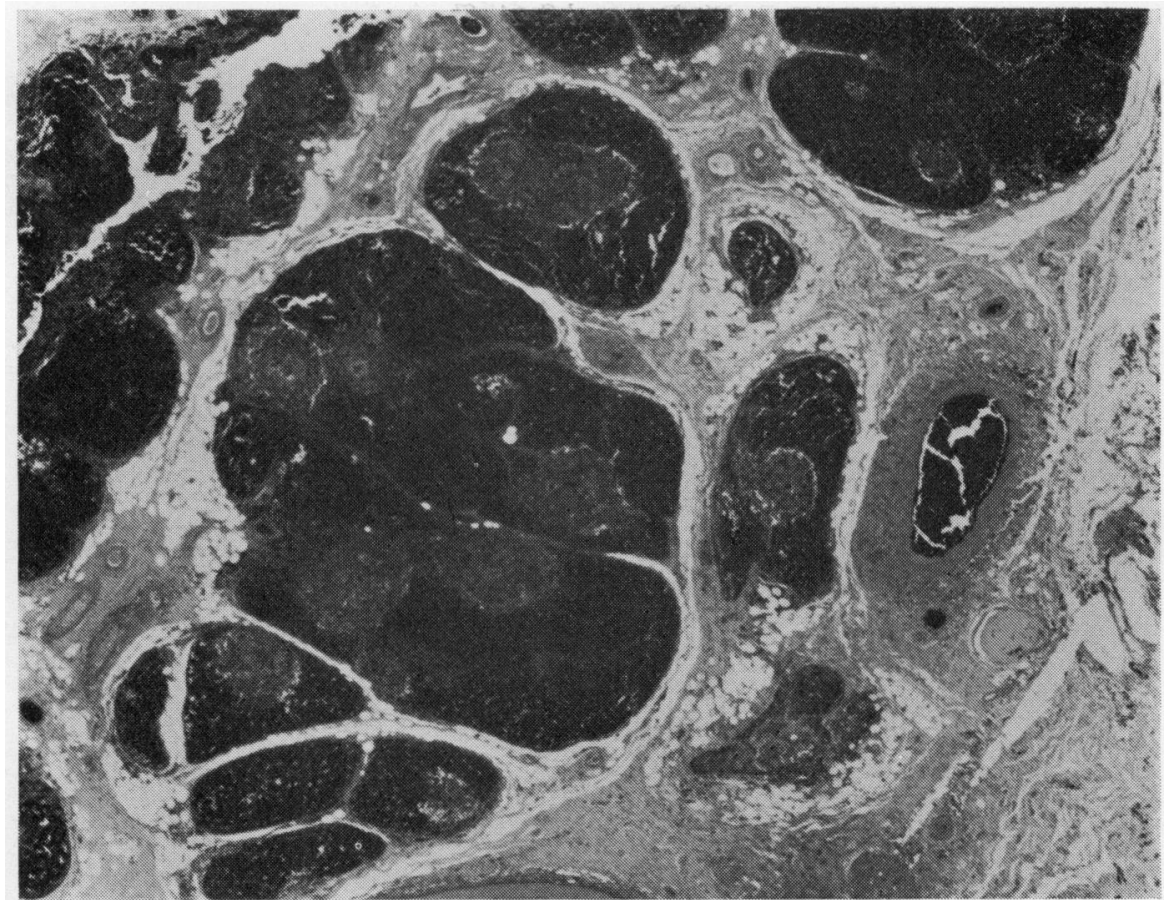

FIG. 5. Lobules of thymic tissue present at the periphery of the teratoma (Haematoxylin and $\operatorname{eosin} \times 20$ ).

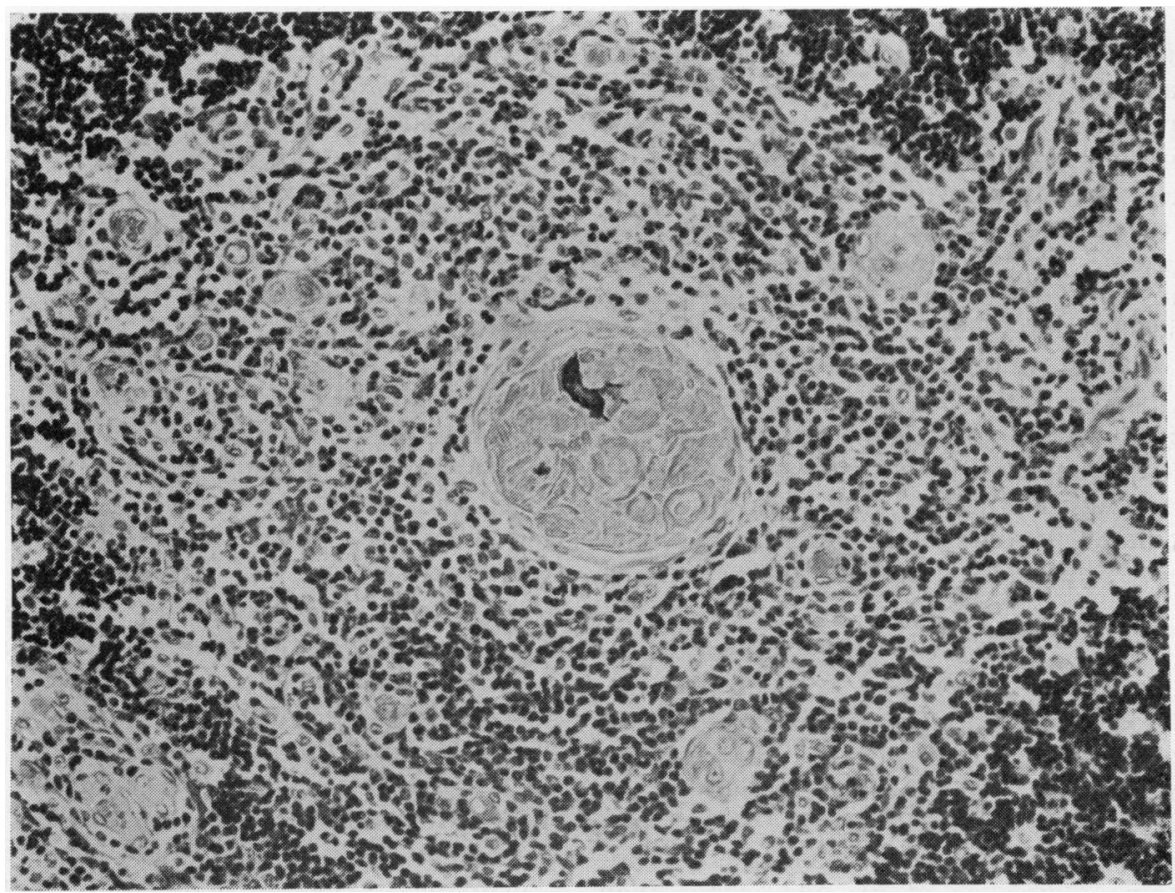

FIG. 6. Thymic tissue showing several Hassall's corpuscles, the largest of which contains a focus of calcification (Haematoxylin and eosin $\times 200$ ). 


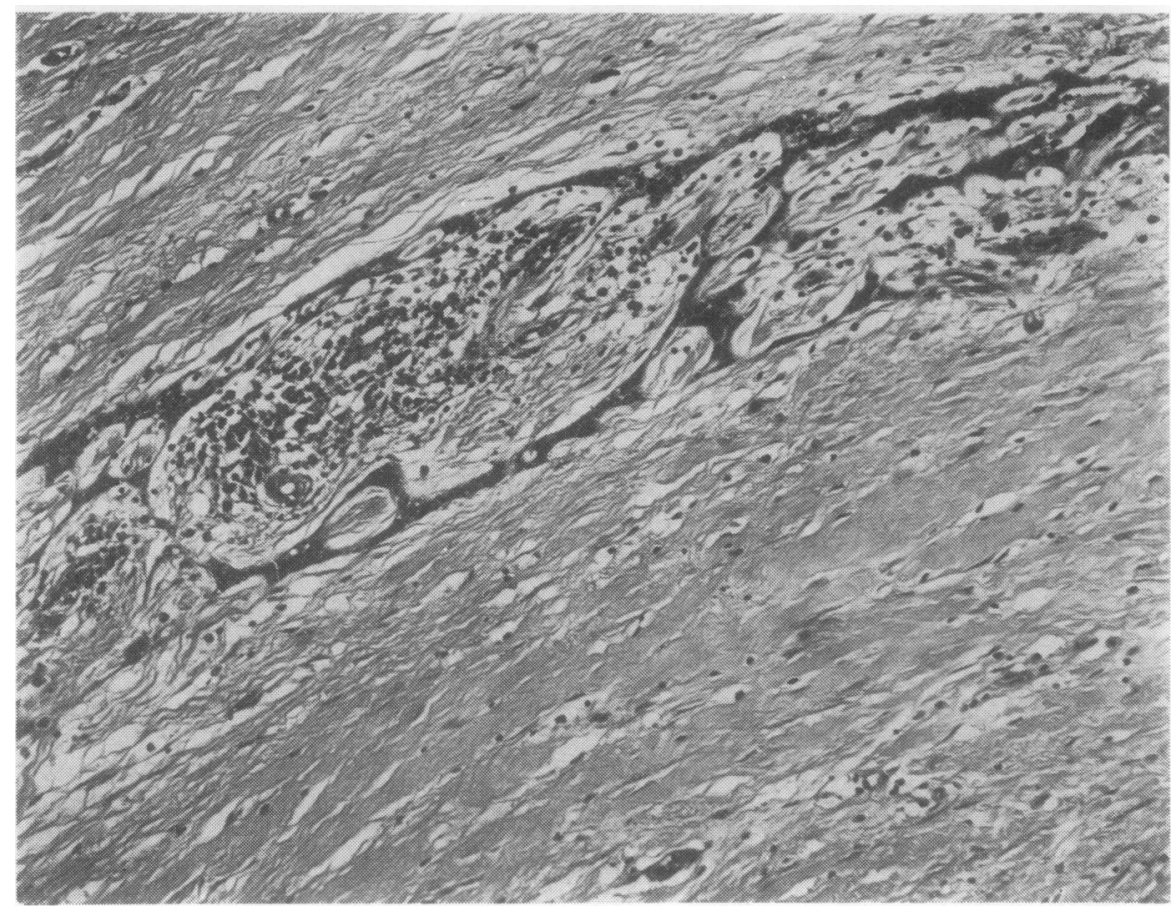

FIG. 7. Strands of attenuated thymic tissue surrounded by fibrous tissue (Haematoxylin and eosin $\times 140$ ).

glands with apocrine and eccrine sweat glands. Occasional hair follicles were also seen (Fig. 3). The polyp was covered by a mixture of squamous and respiratory epithelium with underlying skin appendages and mixed serous and mucous glands. Deep to the surface epithelium of the cyst wall was pancreatic acinar tissue in which islets of Langerhans were present together with clusters of glands and different types of epithelium (Fig. 4). Areas of smooth muscle and fat were also seen. No bone, cartilage or nerve tissue was identified. At the periphery of the teratoma at one point was a prominent focus of thymic tissue with Hassall's corpuscles (Figs 5 and 6), and from this area thin reticulated strands of thymic tissue could be traced completely around the teratoma (Fig. 7).

\section{DISCUSSION}

The rarity of intrapulmonary teratomas contrasts with their relative frequency in the anterior mediastinum which is their third commonest site in the body. In a review article in 1944 Rusby collected 245 examples of teratoma of the anterior mediastinum, adding six of his own. Since then many more have been described in the literature, whereas up to the present time only 19 cases of intrapulmonary teratoma have been reportedo़ although in some the exact site of origin has been doubtful or histology has been lacking. Trivedio Mehta, and Nanavaty (1966) reported a case oe their own and reviewed the literature of the previous 15 cases, and since then further case have been described by Bateson, Hayes, and Woo-Ming (1968), Gautam (1969), and Pounc and Willis (1969). Apart from this last case which occurred in an infant, the age of presenta tion has varied from 16 to 66 years. The com? monest site in the lung has been the left upper lobe, and of the 16 reports with details of the nature of the tumour, nine have been benign and seven malignant.

Our case was similar to that described be Collier et al. (1959) in that the cystic cavity of the teratoma was in direct communication with the distal part of the segmental bronchus. Pancreatice acinar tissue, with or without islets of Langerhans, is a usual feature of the anterior mediastina? and intrapulmonary teratomas but is rare im teratomas in the gonads and other sites.

Thymic tissue in association with intrapulo monary teratoma has not been described before 
However, its association with teratoma of the anterior mediastinum is well recognized. Schlumberger (1946), in a study of 16 cases of anterior mediastinal teratoma, found thymic tissue in the capsule in four instances, and emphasized that sometimes only parts of the teratoma were available for detailed microscopical study. Since then Inada and Nakano (1958), in a histological study of 15 cases of mediastinal teratoma, found residual thymic tissue adjacent to the capsule or in marginal areas mixed with tumour tissue in 11 of 15 cases, and in one of them completely surrounding the tumour.

From his observations Schlumberger proposed that the site of development of anterior mediastinal teratoma was in thymic tissue, a view originally put forward by Marchand in 1833. The origin of teratoma in the thorax, away from the usual site of the thymus in the anterior mediastinum, could be explained by displacement or early separation of thymic tissue during embryogenesis. Pound and Willis (1969), trying to explain the mode of origin of pulmonary teratoma, suggest that in the early embryo the primordial teratomatous focus may lie in such a position in the potential mediastinum that it is caught up and carried by the respiratory outgrowth from the foregut.

In our case it would seem more likely that the teratoma was arising in thymic tissue and not that the thymic tissue was one of the components of the teratoma, since thymic tissue could be traced completely around the periphery of the tumour. In some places the thymic tissue was obvious, with demarcation into cortical and medullary zones, without evidence of involution and with prominent Hassall's corpuscles. Around most of the tumour, however, and extending from this more obvious thymic tissue, were thin strands of lymphocytic cells with a reticulated pattern. It is easy to appreciate how this attenuated thymic tissue could disappear or be overlooked in a teratoma which has grown beyond a certain size and resulted in compression atrophy.

We should like to thank Mr. A. M. Macarthur for permission to publish the details of this case, Mr. G. Harwood for invaluable technical and photographic help, and Mrs. V. Rivers for typing the manuscript.

\section{REFERENCES}

Bateson, E. M., Hayes, J. A., and Woo-Ming, M. (1968). Endobronchial teratoma associated with bronchiectasis and bronchiolectasis. Thorax, 23, 69.

Collier, F. C., Dowling, E. A., Plott, D., and Schneider, H. (1959). Teratoma of the lung. Archives of Pathology, 68, 138.

Gautam, H. P. (1969). Intrapulmonary malignant teratonid. American Review of Respiratory Disease, 100, 863.

Inada, K. and Nakano, A. (1958). Structure and genesis of the mediastinal teratoma. Archives of Pathology, 66, 183.

Marchand, F. (1833). Ber. d. oberhess. Tesellsch für Natur. u. Heilk, 22, 325.

Pound, A. W. and Willis, R. A. (1969). A malignant teratoma of the lung in an infant. Journal of Pathology, 98, 111.

Rusby, N. L. (1944). Dermoid cysts and teratomata of the mediastinum. Journal of Thoracic Surgery, 13, 169.

Schlumberger, H. G. (1946). Teratoma of the anterior mediastinum in the group of military age-A study of sixteen cases, and a review of theories of genesis. Archives of Pathology, 41, 398.

Trivedi, S. A., Mehta, K. N., and Nanavaty, J. M. (1966). Teratoma of the lung: report of a case. British Journal of Diseases of the Chest, 60, 156.

Requests for reprints to: Dr. D. W. Day, Departments of Morbid Anatomy and Surgery, King's College Hospital, Denmark Hill, London SE5 8RX. 